\title{
Matemágica e Resolução de Problemas
}

\author{
Mathemagic and Problem Solving
}

\author{
Viviane de Oliveira Santos \\ Universidade Federal de Alagoas (UFAL), Maceió, AL, Brasil \\ viviane.santos@im.ufal.br \\ Vagner Lopes de Almeida \\ Universidade Federal de Alagoas (UFAL), Maceió, AL, Brasil \\ vagnermhat@gmail.com
}

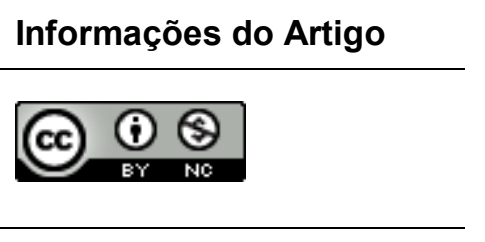

Histórico do Artigo

Submissão: 01 de abril de 2018.

Aceite: 25 de junho de 2018.

Palavras-chave

Ensino de Matemática

Mágica

Resolução de Problemas

Aprendizagem

Lúdico

\section{Resumo}

O objetivo deste artigo é apresentar algumas mágicas que utilizam propriedades matemáticas e apresentá-las como uma proposta de uso em sala de aula, juntamente com a Resolução de Problemas. Tal estratégia pode melhorar a participação e aproveitamento dos alunos, estimular o raciocínio matemático, a criatividade, a capacidade de resolver problemas, desenvolver a concentração e a socialização. Levando em consideração os conteúdos abordados na Educação Básica, selecionamos e descrevemos uma lista de mágicas, detalhamos os conteúdos e habilidades predominantes em cada uma, mostrando a Matemática por trás de cada truque. Além do raciocínio lógico, usamos conhecimento de álgebra básica e aritmética para justificá-los. Ao revelar o segredo de cada mágica, percebe-se que é possível trabalhar vários conteúdos matemáticos que podem auxiliar a aprendizagem. A escolha de apresentar algumas mágicas com suas resoluções e com alguns possíveis questionamentos é no sentido de oferecer ao professor um material de apoio e ajudá-lo a trabalhar com as estratégias de seus alunos. Como a Matemática também deve ser vista como um conhecimento para desenvolver o raciocínio, aliar mágica a resolução de problemas pode ser um método eficiente para o estímulo ao desenvolvimento lógico.

\section{Abstract}

The objective of this article is to present some magics that use mathematical properties and present them as a proposal for classroom use, along with problem solving. Such strategy can increase participation and improvement of students, stimulate mathematical thinking, creativity, problem-solving skills, develop concentration and socialization. Taking into account the contents covered in Basic Education, we select and describe a list of magic, detail the contents and skills predominant in each one, showing the Mathematics behind each trick. In addition to logical reasoning, we use basic algebra and arithmetic knowledge to justify them. By revealing the secret of each magic, one realizes that it is possible to work various mathematical contents that can aid learning. The choice of presenting some magics with its resolutions and some possible questions is to offer support material to the teacher and help him to work with the strategies of his students. Since Mathematics must also be seen as a knowledge to develop reasoning, allying magic to problem solving can be an efficient method for stimulating logical development.

\section{Introdução}

Visando despertar o interesse pelo estudo da matemática e contribuir para a melhoria da aprendizagem, professores buscam alternativas no modo de explorar conteúdos matemáticos. De acordo com os Parâmetros Curriculares Nacionais (PCN): 
É consensual a ideia de que não existe um caminho que possa ser identificado como único e melhor para o ensino de qualquer disciplina, em particular, da Matemática. No entanto, conhecer diversas possibilidades de trabalho em sala de aula é fundamental para que o professor construa sua prática". (BRASIL, 1997, p. 32).

O processo de resolução de problemas pode auxiliar na construção do conhecimento matemático, tendo o professor como mediador e orientador do processo ensino-aprendizagem, responsável pela sistematização do novo conhecimento. Aliado a isso, podemos usar a matemágica $^{1}$ (mágica que utiliza propriedades matemáticas) para motivar ou introduzir algum conteúdo, despertando nos alunos a curiosidade e a vontade de desvendar o truque, bem como para compreender a matemática que está por trás de cada truque. Desta forma, fizemos uma pesquisa de mágicas abordando vários conteúdos matemáticos, refletindo sobre os conceitos matemáticos e propriedades numéricas apresentadas.

Usar o lúdico e o método da resolução de problemas é uma possibilidade de auxiliar no processo ensino-aprendizagem da matemática, pois estimulam o convívio em grupo, desenvolvem o raciocínio e possibilitam uma aprendizagem divertida. Como veremos, as atividades propostas nesse artigo podem estimular o raciocínio e a imaginação. Temos então uma possibilidade para estimular a confiança e a aprendizagem dos alunos.

Um professor que estimula seus alunos em sala de aula se torna uma peça chave no ensinoaprendizagem, proporcionando formas diferenciadas de conhecimento e tornando o aluno mais independente, isso quer dizer que o professor passa a ser um mediador do conhecimento, tendo um papel de auxiliador.

A apresentação de algumas matemágicas é uma proposta para incentivar os professores de matemática a utilizarem as mágicas juntamente com a resolução de problemas, visando despertar o interesse do aluno pelo estudo da matemática e contribuir para a melhoria da aprendizagem matemática.

De acordo com os Parâmetros Curriculares Nacionais de Matemática (BRASIL, 1997, p. 20), “[...] é importante destacar que a matemática deverá ser vista pelo aluno como um conhecimento que pode favorecer o desenvolvimento do seu raciocínio, de sua sensibilidade expressiva, de sua sensibilidade estética e de sua imaginação". Desta forma, aliar matemágica a resolução de problemas pode ser um método eficiente no sentido de aliar o lúdico com o estímulo ao desenvolvimento lógico.

\footnotetext{
${ }^{1}$ Alguns autores usam o termo magia matemática, por exemplo, (BASTOS, 2015), e outros usam matemágica, por exemplo, (OLIVEIRA et al., 2013) e (ALMEIDA, 2014).
} 


\title{
2. Referencial Teórico
}

\subsection{Evolução da Matemágica}

Não há como negar o fascínio que a mágica exerce sobre a mente humana, o de desejo de querer entender e explicar as coisas a nossa volta é algo natural.

\begin{abstract}
É isso que garante o encanto sobre a mágica realizada. O espectador sabe que não há nada de sobrenatural na magia realizada, mas precisa pensar muito para descobrir como ela foi realizada. Os mágicos mais famosos usam artifícios e efeitos mais elaborados, e que algumas vezes fogem ao raciocínio comum. Trata-se de uma arte alicerçada primordialmente na sua habilidade e na sua capacidade de persuadir. Seus efeitos são como um quebra-cabeça, que além de alegrar e divertir torna-se um desafio à inteligência dos espectadores, que não conseguem explicações lógicas para aquilo que veem. (FURTADO, 2008, p. 20).
\end{abstract}

Não sabemos precisamente quando a mágica surgiu, mas há indícios da presença da arte mágica desde a antiguidade. O mais antigo registro de mágica é um papiro egípcio, no qual "são descritas as performances que um homem chamado Dedi fazia perante a corte do faraó Cheops e entretinha os escravos que construíam as pirâmides, por volta de 2000 a.C." No Brasil, os primeiros registros da arte mágica ocorreram no início do século $X X$ com a publicação de Revelações de magia brasileira, de Frederico Costa Brito, em 1903. (GARAT et al., 2005, p. 54-55).

Segundo Bastos (2015, p. 2-3), Wade H. Sherard no livro "Mathemagic in the classroom" relata que é possível considerar que a magia matemática teve origem no século XVII, pois vários truques aritméticos foram incluídos nas obras de Claude Gaspar Bachet nos anos de 1612, 1624 e 1694, dos quais alguns foram baseados em escritos de matemáticos como Alcuin, Luca Pacioli di Burgo, Tartaglia e Cardano. Luca Pacioli, em seu manuscrito "De Viribus Quantitatis", 1490, descreve pela primeira vez um truque relacionado com matemática e Girolamo Cardano, no seu livro "Subtilitate rerum", 1551, apresentou a descrição de um truque de cartas pela primeira vez. "No entanto, o interesse atual pela magia matemática pode ser atribuído aos escritos de W W Rouse Ball (1850-1925) e Martin Garden (1914-2010), grandes impulsionadores da matemática recreativa."

Ball publicou o seu clássico "Mathematical Recreations \& Essays", em 1892. Martin Garden ficou conhecido pela publicação dos artigos "Mathematical Games" entre 1957 e 1981, os quais muitos eram dedicados à magia matemática, e o seu livro "Mathematics, Magic and Mistery" publicado pela primeira vez em 1956, talvez foi a primeira etapa da magia matemática. (BASTOS, 2015, p. 3).

A literatura de magia matemática cresceu e podemos encontrar uma variedade de truques em livros, artigos, dissertações etc. No Brasil existem pessoas que colaboram com a divulgação científica em matemática, ministrando palestras e oficinas sobre matemágicas e seus mistérios, como Pedro Luiz Aparecido Malagutti e João Carlos Vieira Sampaio (SAMPAIO; MALAGUTTI, 2006). Além disso, o uso da matemágica em sala de aula pode melhorar o desempenho dos alunos na disciplina matemática, como por exemplo o caso da professora Leila Graziela de Mendonça 
Castro, noticiado em iG São Paulo (2017). A professora decidiu levar truques de mágica e ilusionismo para as aulas de matemática, conseguindo elevar as notas de alunos do Ensino Médio.

\subsection{Resolução de Problemas}

Dentre alguns métodos para o ensino e aprendizagem em Matemática, está a resolução de problemas, o qual é considerado como um método para potencializar o raciocínio lógicomatemático, bem como desenvolver o pensamento e criatividade. (D’AMBROSIO, 2008). Além disso, "a maioria (senão todos) dos importantes conceitos e procedimentos matemáticos pode ser melhor ensinado através da Resolução de Problemas" (ONUCHIC; ALLEVATO, 2009, p. 223).

O ensino de Matemática passou por várias reformas. No início do século XX, o trabalho era apoiado na repetição e, anos depois, a orientação passou a ser a aprendizagem matemática com compreensão. Foi neste momento que se começou a falar sobre resolução de problemas. (ONUCHIC, 1999, p. 201). Depois de várias reformas no ensino de matemática, no início da década de 70 foram iniciadas investigações sobre resolução de problemas e suas implicações curriculares. (ONUCHIC; ALLEVATO, 2009, p. 215).

Segundo Andrade (1998, p. 7-8 apud Onuchic, 1999, p. 201),

A primeira vez em que a resolução de problemas é tratada como um tema de interesse para professores e alunos, nos níveis superiores, foi a partir do livro How to solve it, de Polya, cuja primeira edição data de 1945. Antes deste período, entretanto, houve algumas experiências e alguns estudos enfatizando os produtos da resolução de problemas.

Porém, a resolução de problemas destacou-se como foco do ensino da Matemática no documento "Agenda para Ação" da "National Council of Teachers of Mathematics" (NCTM) dos Estados Unidos, publicada em 1980, o qual apresentou recomendações para o ensino de Matemática (BRASIL, 1997). O que se defende quando colocamos o foco na Resolução de Problemas é uma proposta que poderia ser resumida nos seguintes princípios:

- O ponto de partida da atividade matemática não é a definição, mas o problema. No processo de ensino e aprendizagem, conceitos, ideias e métodos matemáticos devem ser abordados mediante a exploração de problemas, ou seja, de situações em que os alunos precisem desenvolver algum tipo de estratégia para resolvê-las;

- O problema certamente não é um exercício em que o aluno aplica, de forma quase mecânica, uma fórmula ou um processo operatório. Só há problema se o aluno for levado a interpretar o enunciado da questão que lhe é posta e a estruturar a situação que lhe é apresentada;

- Aproximações sucessivas ao conceito são construídas para resolver um certo tipo de problema; num outro momento, o aluno utiliza o que aprendeu para resolver outros, o que exige transferências, retificações, rupturas, segundo um processo análogo ao que se pode observar na história da Matemática; 
- O aluno não constrói um conceito em resposta a um problema, mas constrói um campo de conceitos que tomam sentido num campo de problemas. Um conceito matemático se constrói articulado com outros conceitos, por meio de uma série de retificações e generalizações;

- A resolução de problemas não é uma atividade para ser desenvolvida em paralelo ou como aplicação da aprendizagem, mas uma orientação para a aprendizagem, pois proporciona o contexto em que se pode apreender conceitos, procedimentos e atitudes matemáticas. (BRASIL, 1997, p. 20).

Durante a década de 80 , foram desenvolvidos muitos recursos em resolução de problemas e muito desse material passou a ajudar os professores a usar a resolução de problemas no seu trabalho. Mas o trabalho dessa década não chegou a um bom termo, "[...] possivelmente devido a uma falta de concordância entre as diferentes concepções que pessoas e grupos tinham sobre o significado de Resolução de Problemas ser o foco da Matemática escolar". (ONUCHIC; ALLEVATO, 2009, p. 216).

Em 1989, o NCTM publicou seu primeiro documento "Standards" e iniciou uma revolução na Matemática escolar. Van de Walle (2001 apud ONUCHIC; ALLEVATO, 2009, p. 221) coloca para os professores de Matemática como um dos componentes básicos em suas atividades: "[...] ter habilidade em planejar e selecionar tarefas e, assim, fazer com que os alunos aprendam Matemática num ambiente de Resolução de Problemas [...]".

Finalizando a década de 80 , os pesquisadores começaram a discutir aspectos didáticos e pedagógicos da Resolução de Problemas, passando "a ser pensada como uma metodologia de ensino, como um ponto de partida e um meio de ensinar matemática" (ONUCHIC, 1999, p. 207).

\section{Metodologia}

Existem alguns trabalhos que envolvem matemágicas, os quais basicamente apresentam as mágicas e as revelações dos truques. Então, tivemos a ideia de aliar as matemágicas com a resolução de problemas, no sentido de apresentar uma proposta para o professor utilizar as matemágicas em sala de aula.

As mágicas ativam a curiosidade e facilmente virão questionamentos do tipo "como ele fez isso?". Deste modo, explorar a resolução de problemas neste contexto é bem propício, pois estamos numa situação de um problema que inicialmente não se tem a solução e é possível criar estratégias para resolvê-lo. Segundo Smole et al. (2000, p. 13),

Para uma criança, assim como para um adulto, um problema é toda situação que ela enfrenta e não encontra solução imediata que the permita ligar os dados de partida ao objetivo a atingir. A noção de problema comporta a ideia de novidade, de algo nunca feito, de algo ainda não compreendido. 
Trabalhar as mágicas com a resolução de problemas é uma proposta que pode proporcionar um ambiente instigante, desafiador e divertido, além de resultar num melhor aproveitamento no processo de ensino e aprendizagem matemática. Para isso, fizemos uma pesquisa bibliográfica na busca de mágicas envolvendo matemática e selecionamos algumas mágicas envolvendo vários conteúdos matemáticos, que podem ser trabalhadas a partir do $6^{\circ}$ ano do Ensino Fundamental.

$\mathrm{Na}$ dissertação (ALMEIDA, 2017), dividimos as mágicas da seguinte forma: mágicas envolvendo expressões algébricas, mágicas envolvendo múltiplos de nove, mágicas aritméticas, mágicas envolvendo mudança de base e outros truques. Neste artigo, escolhemos algumas mágicas dessas divisões para exemplificar aos professores que as matemágicas podem ser trabalhadas em sala de aula juntamente com a resolução de problemas.

Três modos diferentes de abordar resolução de problemas são apresentados por Schroeder e Lester (1989 apud ONUCHIC, 1999, p. 206): "ensinar sobre resolução de problemas, ensinar a resolver problemas e ensinar matemática através da resolução de problemas". A abordagem de ensinar sobre a resolução de problemas procura ressaltar o modelo de resolução de problemas de Polya ou alguma variação, no qual descreve um conjunto de quatro fases interdependentes no processo de resolver problemas. No "ensinar a resolver problemas", concentra-se em como a matemática é ensinada e nas aplicações. Enquanto que "ensinar através da resolução de problemas", pensa-se em metodologia de ensino, sendo um ponto de partida e algo para se ensinar matemática. (ONUCHIC, 1999, p. 206).

Onuchic (1999, p. 207) diz que "embora na teoria as três concepções de ensinar resolução de problemas matemáticos possam ser separadas, na prática elas se superpõem e acontecem em várias combinações e sequências". Neste sentido, nossa proposta segue uma combinação das três concepções.

Em cada uma das mágicas neste artigo, são apresentados o enunciado e as etapas do método de Polya (2006), seguindo o roteiro: explicação, questionamento para compreensão, questionamento para resolver o plano, execução do plano, questionamento para retrospectiva, sugestões e observações. Além disso, é mencionado os conteúdos que podem ser explorados e a partir de qual série podem ser aplicadas.

Como afirmam Onuchi e Allevato (2009, p. 223), "Não há dúvida de que ensinar com problemas é difícil. As tarefas precisam ser planejadas ou selecionadas a cada dia, considerando a compreensão dos alunos e as necessidades do currículo". Além disso, para termos um bom ambiente matemático, o professor é imprescindível e cada aula deve possuir três partes importantes: antes, durante e depois.

Para a primeira parte, o professor deve garantir que os alunos estejam mentalmente prontos para receber a tarefa e assegurar-se de que todas as expectativas estejam claras. Na fase 'durante', os alunos trabalham e o professor observa e avalia esse trabalho. Na terceira, 'depois', o professor aceita a solução dos alunos sem avaliálas e conduz a discussão enquanto os alunos justificam e avaliam seus resultados e métodos. Então, o professor formaliza os novos conceitos e novos conteúdos construídos. (ONUCHIC; ALLEVATO, 2009, p. 221). 
Desta forma, ressaltamos que no tópico a seguir, apresentamos possíveis questionamentos e estratégias de soluções, pois a abordagem em si de cada mágica irá depender da socialização com a turma, a depender do que os alunos questionem e apresentem como estratégias. De qualquer forma, achamos interessante apresentar algumas sugestões no sentido de auxiliar os professores em seu planejamento prévio. Acreditamos também ser importante o professor saber a resolução da mágica e ter conhecimento de possíveis questionamentos, mesmo que ao aplicar surjam outros questionamentos e estratégias.

\section{Resultados e Discussão}

Após a pesquisa bibliográfica de mágicas envolvendo a matemática, selecionamos algumas mágicas envolvendo vários conteúdos matemáticos. O processo de escolha das mágicas seguiu visando os conteúdos matemáticos envolvidos que pudessem ser trabalhados na Educação Básica e, de acordo com o conteúdo, informamos a partir de qual série a mesma pode ser trabalhada.

De acordo com Polya (2006), entre os vários tipos de problemas, temos os problemas de determinação e os de demonstração. Neste contexto notaremos que as mágicas aqui expostas serão problemas de determinação ou de demonstração.

O objetivo de um 'problema de determinação' é encontrar um certo objeto, a incógnita do problema. A incógnita é aquilo que se procura ou de que necessita. Para resolver um 'problema de determinação' é preciso, com grande exatidão, as suas partes principais, a incógnita, os dados e a condicionante. Por outro lado, o objetivo de um 'problema de demonstração' é mostrar conclusivamente que certa afirmativa, claramente enunciada, é verdadeira ou, então, que é falsa. Se o 'problema de demonstração' for um problema matemático comum, suas partes principais serão a hipótese e a conclusão do teorema que tiver de ser provado ou refutado. (POLYA, 2006, p. 142-143).

Polya (2006, p. 4) aborda a resolução de problemas em quatro fases:

Primeiro, temos de compreender o problema, temos de perceber claramente o que é necessário. Segundo, temos de ver como os diversos itens estão interrelacionados, como a incógnita está ligada aos dados, para termos a ideia da resolução, para estabelecermos um plano. Terceiro, executamos o nosso plano. Quarto, fazemos um retrospecto da resolução completa, revendo-a e discutindo-a. 
Quadro 1 - Resumo do Método de Polya.

\section{COMPREENSÃO DO PROBLEMA}

\begin{tabular}{|c|c|}
\hline $\begin{array}{l}\text { Primeiro } \\
\text { É preciso } \\
\text { compreender o } \\
\text { problema. }\end{array}$ & $\begin{array}{l}\text { Qual é a incógnita? Quais são os dados? Qual é a condicionante? É possível } \\
\text { satisfazer a condicionante? A condicionante é suficiente para determinar a } \\
\text { incógnita? Ou é insuficiente? Ou redundante? Ou contraditória? Trace uma } \\
\text { figura. Adote uma notação adequada. Separa as diversas partes da } \\
\text { condicionante. É possível anotá-las? }\end{array}$ \\
\hline \multicolumn{2}{|r|}{ ESTABELECIMENTO DE UM PLANO } \\
\hline $\begin{array}{c}\text { Segundo } \\
\text { Encontra a conexão } \\
\text { entre os dados e a } \\
\text { incógnita. } \\
\text { É possível que seja } \\
\text { obrigado a considerar } \\
\text { problemas auxiliares } \\
\text { se não puder } \\
\text { encontrar uma } \\
\text { conexão imediata. } \\
\text { É preciso chegar afinal } \\
\text { a um plano para a } \\
\text { resolução. }\end{array}$ & $\begin{array}{l}\text { Já o viu antes? Ou já viu o mesmo problema apresentado sob uma forma } \\
\text { ligeiramente diferente? Conhece um problema correlato? Conhece um problema } \\
\text { que Ihe poderia ser útil? Considere a incógnita! Procure pensar num problema } \\
\text { conhecido que tenha a mesma incógnita ou outra semelhante. Eis um problema } \\
\text { correlato e já antes resolvido. É possível utilizá-lo? É possível utilizar o seu } \\
\text { resultado? É possível utilizar o seu método? Deve-se introduzir algum elemento } \\
\text { auxiliar para tornar possível a sua utilização? É possível reformular o problema? } \\
\text { É possível reformulá-lo ainda de outra maneira? Volte às definições. Se não } \\
\text { puder resolver o problema proposto, procure antes resolver algum problema } \\
\text { correlato. É possível imaginar um problema correlato mais acessível? Ou um } \\
\text { que seja mais genérico? Um problema mais específico? Um problema análogo? } \\
\text { É possível resolver uma parte do problema? Mantenha apenas uma parte da } \\
\text { condicionante, deixa a outra de lado; até que ponto fica assim determinada a } \\
\text { incógnita? Como pode ela variar? É possível obter dos dados alguma coisa de } \\
\text { útil? É possível pensar em outros dados apropriados para determinar a } \\
\text { incógnita? É possível variar a incógnita, ou os dados, ou todos eles, se } \\
\text { necessário, de tal maneira que fiquem mais próximos entre si? Utilizou todos os } \\
\text { dados? Utilizou toda a condicionante? Levou em conta todas as noções } \\
\text { essenciais implicadas no problema? }\end{array}$ \\
\hline \multicolumn{2}{|r|}{ EXECUÇÃO DO PLANO } \\
\hline $\begin{array}{c}\text { Terceiro } \\
\text { Executa o seu plano. }\end{array}$ & $\begin{array}{l}\text { Ao executar o seu plano de resolução, verifique cada passo. É possível verificar } \\
\text { claramente que o passo está correto? É possível demonstrar que ele está } \\
\text { correto? }\end{array}$ \\
\hline \multicolumn{2}{|r|}{ RETROSPECTO } \\
\hline $\begin{array}{l}\text { Quarto } \\
\text { Examine a solução } \\
\text { obtida. }\end{array}$ & $\begin{array}{l}\text { É possível verificar o resultado? É possível verificar o argumento? É possível } \\
\text { chegar ao resultado por um caminho diferente? É possível perceber isto num } \\
\text { relance? É possível utilizar o resultado, ou o método, em alqum outro problema? }\end{array}$ \\
\hline
\end{tabular}

Fonte: Polya (2006, n.p.).

A execução do plano em cada problema, depende da estratégia formulada pelos alunos em sala, o que inserimos aqui é uma possível resolução. Devemos lembrar que

Resolução de Problemas coloca o foco da atenção dos alunos sobre idéias (sic.) e sobre o "dar sentido". Ao resolver problemas os alunos necessitam refletir sobre as idéias (sic.) que estão inerentes e/ou ligadas ao problema. (ONUCHIC; ALLEVATO, 2009, p. 223).

As mágicas a seguir e o formato em que são apresentadas é para auxiliar o professor a trabalhar com a matemágica e a resolução de problemas. Além disso, vale destacar que outras mágicas podem ser abordadas neste mesmo sentido e os próprios alunos também poderão criar suas matemágicas.

Mágicas envolvendo expressões algébricas podem ser trabalhadas a partir do $7^{\circ}$ ano explorando, por exemplo, os conteúdos equação do primeiro grau, sistemas de equações e álgebra básica dos monômios e polinômios. Vejamos algumas: 
- Um número pensado: Pense em um número e multiplique ele por 3. Some 6 ao resultado, divida o resultado por 3 e tire o número pensado. Não importa o número pensado, magicamente ao final teremos 2 como resultado. (adaptado de Alves (2015, p. 13)).

Explicação: De acordo com Polya (2006), podemos classificar essa mágica, como um problema de demonstração, pois devemos mostrar que seguindo as etapas do truque ao final teremos 2 como resultado.

Questionamentos para compreensão: Qual é a incógnita? Quais os dados? Existe alguma notação adequada? Questionamento para estabelecer o plano: Existe um problema mais específico? Algum problema correlato? Semelhante? É possível reformular o problema? É possível resolver parte do problema? É possível variar a incógnita, ou os dados, ou todos eles? Todos os dados foram usados? Todas as condições? Algo mais específico e natural seria testar alguns números, por exemplo, suponha que o número pensado tenha sido 5 , temos, $(3 \times 5+6) \div 3=7$ e $7-5=2$. Esse teste pode auxiliar a compreensão do problema e o estabelecimento do plano.

Execução do plano: Sendo $x$ o número pensado, temos

$$
\frac{3 x+6}{3}-x=\frac{3 x}{3}+\frac{6}{3}-x=x+2-x=2
$$

Questionamentos para retrospectiva: É possível verificar o resultado ou argumento? É possível chegar ao resultado por um caminho diferente? É possível utilizar o resultado, ou o método, em algum outro problema?

Podemos usar outras propriedades, por exemplo, temos que $3 x+6=3(x+2)$ e ao dividir essa expressão por 3 , temos, $x+2$ e assim $(x+2)-x=2$.

Sugestões e observações: Essa é uma boa mágica para introduzir conteúdos com álgebra básica: expressões algébricas e equações do primeiro grau.

- Descobrindo dois números - peça de dominó: Peça a um amigo que escolha uma peça qualquer de um dominó em segredo. Agora peça-lhe que multiplique um dos números dessa peça por $\mathbf{5}$, some $\mathbf{7}$ ao resultado, em seguida multiplique o resultado por $\mathbf{2}$, adicione a esse resultado o outro número da peça de dominó e que finalmente tire $\mathbf{1 2}$ do resultado. Agora revelando o resultado, saberemos qual foi a peça de dominó escolhida. (ALMEIDA, 2014).

Explicação: Temos que dado o resultado, devemos determinar dois números. Podemos considerar essa mágica como um problema de determinação.

Compreensão do problema: Qual é a incógnita? Quais os dados? Qual é a condicionante? A condicionante é suficiente para determinar a incógnita? Existe alguma notação adequada? Nesse caso, temos duas incógnitas e temos uma notação adequada.

Estabelecimento do plano: Existe algum problema semelhante? Algum problema que possa ser útil? Algum problema correlato que já foi resolvido antes? É possível utilizar seu resultado? É possível utilizar seu método? 
Execução do plano: Sendo $x$ e $y$ os números da peça de dominó, $x \in \mathbb{N}, y \in \mathbb{N}, x \leq 6$ e $y \leq$ 6, queremos determinar $x$ e $y$. Temos:

$$
(5 x+7) \times 2+y-12=10 x+14+y-12=10 x+y+2
$$

Supondo que o resultado seja 25 , temos, $10 x+y+2=25$, assim $10 x+y=23=10 \times 2+$ 3.

$$
\text { Logo, } x=2 \text { e } y=3 \text {. }
$$

Retrospectiva: É possível chegar a conclusão por um caminho diferente? Temos a condição de que $x \in \mathbb{N}, y \in \mathbb{N}, x \leq 6$ e $y \leq 6$. Fazendo uma retrospectiva do problema, temos que $x$ representa a quantidade de dezenas e $y$ a quantidade de unidades. Portanto ao usar esse roteiro para descobrir dois números, temos que para o truque funcionar, $x$ e $y$ são naturais tais que, $x \leq 9$ e $y \leq 9$. Outra possibilidade é usar o algoritmo da divisão, isto é, dado $10 x+y=23$, temos que $x$ é o quociente da divisão de 23 por 10 e y é o resto.

Sugestões e observações: Podemos trabalhar conteúdos como: expressões algébricas, equações do primeiro grau, sistema de numeração decimal e o algoritmo da divisão. É notável que, matematicamente, a mágica pode ser feita de maneira mais simples, mas o número de operações ajuda o mágico a iludir os espectadores. O professor como mediador pode pedir aos alunos que criem outras mágicas a partir desse exemplo.

A partir do $6^{\circ}$ ano podemos trabalhar as mágicas envolvendo múltiplo de nove, nas quais podemos abordar assuntos como múltiplos, divisores, divisibilidade e o sistema de numeração decimal. Vejamos algumas:

- O Dígito Oculto: O mágico pede a um espectador que pegue um número com $\mathbf{5}$ algarismos diferentes e some esses algarismos. Em seguida, subtraia a soma do número original. Oculte um dos algarismos desse resultado e finalmente o mágico pede ao espectador que informe a soma dos algarismos restantes. Sabendo a soma dos algarismos restantes, o mágico revela qual foi o dígito ocultado pelo espectador. (DRUCK, 2004).

Explicação: Estamos diante de um problema de determinação, pois devemos determinar o dígito oculto, sabendo a soma dos algarismos restantes.

Compreensão do problema: Quais os dados? Quais as condições? Qual a incógnita? Pelo enunciado os cinco algarismos são distintos e devemos somar os algarismos. Conhecemos alguma notação adequada?

Estabelecimento do plano: Conhecemos algum problema semelhante? Algo mais específico? Supondo, por exemplo, que o número de cinco algarismos seja 24567 , temos,

$$
\begin{aligned}
24567 & =2 \times 10000+4 \times 1000+5 \times 100+6 \times 10+7 \\
& =2 \times 10^{4}+4 \times 10^{3}+5 \times 10^{2}+6 \times 10^{1}+7
\end{aligned}
$$


Seguindo o enunciado, devemos fazer $24567-(2+4+5+6+7)=24567-24=24543$. Suponha que o espectador oculte o dígito 5 , então o espectador deve revelar ao mágico o resultado $(2+4+4+3)=13$. E ao saber que o resultado é 13 , o mágico revela que o algarismo oculto foi o 5 .

Execução do plano: Suponha $N$ sendo um número de 5 dígitos, isto é,

$$
N=\text { abcde }=10^{4} \times a+10^{3} \times b+10^{2} \times c+10^{1} \times d+e
$$

Então,

$$
\begin{aligned}
& 10^{4} \times a+10^{3} \times b+10^{2} \times c+10^{1} \times d+e-(a+b+c+d+e) \\
& =\left(10^{4}-1\right) \times a+\left(10^{3}-1\right) \times b+\left(10^{2}-1\right) \times c+\left(10^{1}-1\right) \times d \\
& =9999 \times a+999 \times b+99 \times c+9 \times d
\end{aligned}
$$

isto é, temos como resultado um múltiplo de 9 .

Sabemos que um número natural é divisível por 9 , se, e somente se, a soma de seus algarismos for divisível por 9 . Na nossa suposição, o espectador revelou o resultado 13 , como a soma deve ser um múltiplo de 9 , temos que o dígito oculto é 5 , pois $5+13=18$.

Retrospectiva: De modo mais geral, seja $A$ um número natural formado pelos algarismos $a_{1}, a_{2}, a_{3}, \ldots, a_{n}$. Se $S=a_{1}+a_{2}+\cdots+a_{n}$, então, $(A-S)$ é um múltiplo de 9.

A demonstração do resultado utiliza a representação decimal do número $A$, isto é,

$A=10^{n-1} \times a_{1}+10^{n-2} \times a_{2}+\cdots+10 \times a_{n-1}+a_{n}$ e $S=a_{1}+a_{2}+\cdots+a_{n}$ então,

$A-S=\left(10^{n-1}-1\right) \times a_{1}+\left(10^{n-2}-1\right) \times a_{2}+\cdots+9 \times a_{n-1}$.

Logo, $(A-S)$ é um múltiplo de 9.

Sugestões e observações: A utilização da notação facilitou a explicação da mágica, além disso, podemos introduzir conteúdos como: divisibilidade, sistema de numeração decimal e expressão algébrica.

- Mágica - bom de ouvido: O mágico pega uma caixa de fósforos com $\mathbf{4 0}$ palitos e pede a um espectador que retire, às escondidas, certo número de palitos; em seguida, que some os algarismos desse número e reponha essa quantidade de palitos. Depois de retirar os palitos e repor a soma, o espectador devolve a caixinha ao mágico que surpreendente balança a caixinha e acerta a quantidade de palitos que ficou nela. (DRUCK, 2004).

Explicação: Podemos considerar esse truque um problema de determinação, pois seguindo as etapas do truque ao final devemos determinar a quantidade de palitos que ficou na caixinha.

Compreensão do problema: Quais os dados? Quais as condições? Alguma notação adequada? Qual a incógnita? O espectador retira certo número de palitos e em seguida soma os algarismos desse número, então temos como parte do problema um número de dois dígitos e temos uma notação adequada para representar um número de dois dígitos. 
Estabelecimento do plano: Conhecemos algum problema semelhante? Algo mais específico?

Dado que a caixa tem 40 palitos, vamos supor que o espectador tire 25 palitos, assim a caixa ficará com $(40-25)=15$ palitos, em seguida ele vai repor $(2+5)=7$ palitos, assim a caixa ficará com $15+7=22$ palitos, isto é, se a caixa inicialmente tem 40 palitos e ao final tem 22 palitos é porque foi tirado dela 18 palitos.

Execução do plano: Seja $x y$ um número de dois algarismos que representa a quantidade de palitos retirados da caixa. Observe que $x y=10 x+y$. Logo, temos:

$$
40-(10 x+y)+(x+y)=40-10 x-y+x+y=40-9 x
$$

Isto é, no fim a quantidade retirada é um múltiplo de 9.

\section{Retrospectiva:}

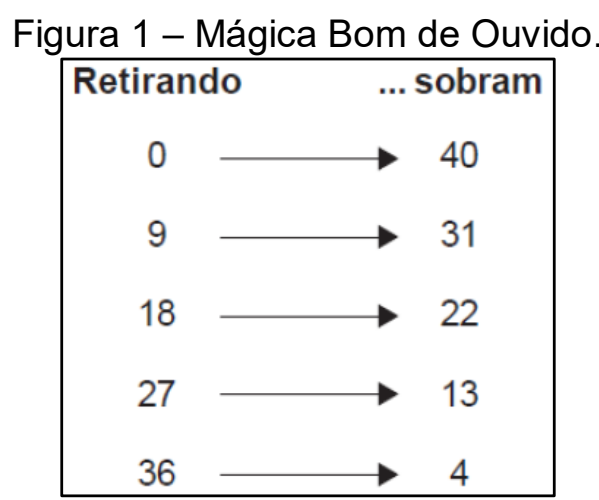

Fonte: Druck (2004, p. 80).

Agora é só treinar o ouvido, pois para cada quantidade retirada teremos um som diferente.

Sugestões e observações: Podemos trabalhar essa mágica ao introduzir assuntos como expressões numéricas, sistema de numeração decimal, equações do primeiro grau e múltiplos de um número.

- Um número e um baralho: Usando um baralho comum, o mágico em segredo coloca a carta 5• (cinco de ouros) na décima posição, contando as cartas pelo topo do baralho. $O$ mágico então pede a um espectador que ele escolha um número natural entre $\mathbf{1 0}$ e 20. Vamos supor que o espectador escolha o número 16, o mágico então passa 16 cartas para a mesa, contando uma a uma, após essa contagem o mágico pergunta qual é a soma de $1+6$, o mágico então pega o montinho de 16 cartas e passa para a mesa 7 cartas, contando uma a uma e mostra a última carta que passou para a mesa que é magicamente o 5 • (Adaptado de Almeida, 2014, p. 68).

Explicação: Podemos considerar esse truque um problema de demonstração, pois seguindo as etapas do truque devemos mostrar que ao final a última carta é $5 \downarrow$. 
Compreensão do problema: Quais os dados? Quais as condições? Alguma figura, desenho ou diagrama que possa ajudar? Esse é um problema onde ter um baralho pode ajuda na compreensão.

Estabelecimento do plano: Conhecemos algum problema semelhante? É possível usar o método do problema anterior? Podemos usar algo mais específico?

Pelo enunciado o espectador escolhe um número natural entre 10 e 20, isto é, temos como parte do problema que a escolha do espectador consiste em escolher um número de dois dígitos e já conhecemos um problema semelhante (mágica bom de ouvido).

Execução do plano: Ao fazer a contagem das dez primeiras cartas para a mesa contando uma a uma, a décima carta (5^) ficará no topo do baralho, ou seja será a primeira carta, o mágico então continua a contagem até o número 16 por exemplo, então temos a décima carta ( $5 \downarrow)+6$ cartas quaisquer em cima dela, então somando $1+6=7$ e contando 7 cartas, uma a uma para a mesa desse montinho de 16 cartas, teremos que a sétima carta será $(5 \bullet)$.

Retrospectiva: É possível verificar o resultado ou argumento? É possível chegar ao resultado por um outro caminho? Outra justificativa é que dado um número de dois dígitos, fazendo a diferença entre o número dado e a soma dos dígitos teremos um múltiplo de 9 , pois, sendo o número da forma $x y=10 x+y$, temos, $10 x+y-(x+y)=9 x$, como o número escolhido pertence ao intervalo ]0;20[ sabemos que tal número é natural, então $x=1$, assim, a diferença entre o número de dois dígitos e a soma dos dígitos nesse caso é exatamente 9 , então ao fazer a contagem das 16 cartas, passando uma a uma para a mesa e em seguida pegando as 7 primeiras cartas desse montinho de 16 cartas vamos notar que a carta do fundo desse monte de 7 cartas é justamente (5») e fazendo a contagem dessas 7 cartas para a mesa, contando uma a uma, o (5») será a carta do topo, isto é, $(5 \Downarrow)$ será a primeira carta o que explica o truque.

Sugestões e observações: Assim como na mágica anterior podemos trabalhar assuntos como expressões numéricas, sistema de numeração decimal, múltiplos de um número e o raciocínio lógico.

Mágicas aritméticas podem ser trabalhadas a partir do $6^{\circ}$ ano e são explorados conteúdos como comutatividade, associatividade, divisibilidade, múltiplos, sistema de numeração decimal, propriedades numéricas, números primos, fatoração e expressões algébricas. Vejamos um exemplo:

- Números da sorte: Escolha um dos números do conjunto $\{1,2,3,4,5,6,7,8,9\}$. Vamos supor que o número escolhido seja 4, assim o mágico pede ao espectador que multiplique 12345679 por 36 e magicamente teremos: $12345679 \times 36=444444444$. Agora escolha um número de dois dígitos, vamos supor que o número escolhido seja 27 , então o mágico pede ao espectador que faça o produto entre 3367 e 81 , e teremos: $3367 \times 81=272727$. (ALMEIDA, 2014). 
Explicação: Estamos diante de um problema de determinação, pois conhecendo o número escolhido podemos determinar qual é o número que deve ser multiplicado por 12345679 e qual número deve ser multiplicado por 3367.

Compreensão do problema: Quais os dados? Qual a pergunta? Qual o objetivo? Temos dois problemas, um envolvendo o número 12345679 e outro envolvendo o número 3367. Pelo enunciado o espectador inicia escolhendo um número natural positivo menor que 10 . Chamando de $N$ esse número natural, o espectador deve fazer $12345679 \times y=N N N N N N N N N$, onde o mágico deve determinar o valor de $y$. Na segunda parte da mágica o espectador escolhe um número natural de dois dígitos, isto é, um número da forma $A B$ e faz $3367 \times z=A B A B A B$. Onde o mágico deve determinar o valor de $z$.

Estabelecimento do plano: Algum problema semelhante? Algo mais específico? De acordo com o enunciado, temos: $12345679 \times 36=444444444$, então, $12345679 \times 9 \times 4=444444444=$ $4 \times 111111111$, assim, $12345679 \times 9=111111111$. Em relação a dezena da sorte, temos, $3367 \times$ $81=272727$, então, $3367 \times 3 \times 27=272727=270000+2700+27=27 \times(10000+100+1)=$ $27 \times(10101)$, isto é, $3367 \times 3 \times 27=27 \times(10101)$, então, $3367 \times 3=10101$.

Execução do plano: Sabemos que $12345679 \times 9=111111111$. Assim, o espectador escolhendo um número $N$, pedimos para que ele faça o produto $12345679 \times 9 \times N=$ $N N N N N N N N N$. Onde $y=9 N$. Sabendo que $3367 \times 3=10101$ e sendo $A B$ um número de dois dígitos, temos, $3367 \times(3 \times A B)=10101 \times A B=A B A B A B$, pois, $10101 \times(A B)=(10000+100+$ 1) $\times(10 A+B)=100000 A+1000 A+10 A+10000 B+100 B+B=A B A B A B$. Logo, $z=3 \times A B$.

Sugestões e observações: Podemos trabalhar assuntos como: sistema de numeração, expressões algébricas, fatoração, números primos e divisibilidade.

\section{Considerações Finais}

É notável que a resolução de problemas, constituído de indagações, é uma ótima ferramenta para aprendizagem. Como sabemos, questionar os "porquês" faz parte da filosofia matemática e tais questionamentos fortalecem nossa aprendizagem.

Diante de qualquer problema existem indagações úteis que podem fazer toda diferença para solução de tal problema e o ato de resolver problemas permite aos estudantes ampliar seus conhecimentos e informações, desenvolvendo sua capacidade de pensar matematicamente e resolver problemas do cotidiano. Assim, os alunos terão oportunidade de aumentar seus conhecimentos por meio de conceitos e procedimentos matemáticos bem como expandir a visão que possuem dos problemas, da matemática e do mundo em geral.

Consideramos que a junção da matemágica com a resolução de problemas pode ser algo bastante produtivo. Em cada mágica, os alunos são convidados a pensar e a tentar criar sua estratégia para descobrir o truque e, para isso, deverão compreender os conteúdos matemáticos envolvidos. Mesmo que não saibam completamente o conteúdo, a curiosidade em descobrir o 
truque da mágica será um grande incentivo para que os mesmos compreendam os conteúdos. Além disso, como sugestão, também pode-se instigar os alunos a criarem outras mágicas baseadas nas que forem apresentadas.

Podemos ter diversos públicos, mas é possível adaptar a aplicação das mágicas de acordo com a turma. $\mathrm{O}$ importante é que os alunos poderão ver a matemática por trás da mágica, entender esta matemática e ainda criar suas próprias mágicas usando o que aprendeu. Os professores serão essenciais em todo processo, pois somente os mesmos conhecem as turmas, saberão os conteúdos que os alunos já sabem e os que sentem dificuldades, e com isso poderão escolher as mágicas, estimular e analisar os questionamentos dos alunos, trabalhar os conteúdos da forma mais adequada para cada turma.

Usando o lúdico podemos despertar o interesse do aluno e, se o aluno estiver realmente interessado, ficará mais fácil para o professor ser mediador e orientador do processo ensino aprendizagem. Conhecer e praticar a resolução de problemas, não se trata apenas de compreender e desenvolver conteúdos, mas estamos oferecendo a chance ao aluno de ter uma visão diferente de mundo, ajudando-o a ser um indivíduo que constrói e modifica o mundo que o cerca.

Acreditamos que a proposta de utilização das matemágicas e resolução de problemas pode colaborar para o ensino de matemática.

\section{Referências}

ALMEIDA, V. L. de. Matemágica: a arte da matemática. Maceió, AL: s.c.p., 2014.

ALMEIDA, V. L. de. Matemágica em sala de aula: uma proposta lúdica usando a resolução de problemas. Dissertação (Mestrado Profissional em Matemática) - Programa de PósGraduação de Mestrado Profissional em Matemática em Rede Nacional. Instituto de Matemática. Universidade Federal de Alagoas. Maceió, 2017.

ALVES, A. G. Mágicas Matemáticas como Metodologia de Ensino. 2015. 66 f. Dissertação (Mestrado Profissional em Matemática em Rede Nacional - PROFMAT) - Centro de Ciências Exatas e de Tecnologia, Universidade Federal de São Carlos, 2015.

BASTOS, I. M. da S. Magia Matemática com Números. 2015. 96 f. Dissertação (Mestrado em Matemática para Professores), Departamento de Matemática, Universidade de Aveiro, 2015.

BRASIL. Ministério da Educação. Secretaria de Educação Fundamental. Parâmetros curriculares nacionais: matemática. Brasília: MEC/SEF, 1997.

D'AMBRosiO, B. S. A Evolução da Resolução de Problemas no Currículo Matemático. In: SEMINÁRIO EM RESOLUÇẤO DE PROBLEMAS. 1. 2008. Anais ... Rio Claro: Unesp, 2008.

DRUCK, S. (Org.). Explorando o ensino da Matemática: atividades. v. 2. Brasília: Ministério da Educação, Secretaria de Educação Básica, 2004.

FURTADO, P. C. Brincadeiras envolvendo jogos de mágica e a matemática. $53 \mathrm{f}$. Relatório de Pesquisa (Curso de Licenciatura em Matemática) - Universidade Comunitária da Região de Chapecó, Chapecó, 2008. 
GARAT, F; ZAMBRONE, G; GUIMARÃES, L; RANI, T. Abracadabra. Eclética. n. 21. p. 54-58, jul./dez. 2005. Disponível em: <http://puc-riodigital.com.puc-

rio.br/media/14\%20-\%20abracadabra.pdf>. Acesso em: 31 mar. 2018.

IG SÃO PAULO. Professora usa mágica em sala de aula e melhora aprendizado em escola pública. 04/04/2017. Disponível em: <http://ultimosegundo.ig.com.br/educacao/2017-0404/matematica-magica.html>. Acesso em: 31 mar. 2018.

OLIVEIRA, T. J. de; MASCARELLO, T. H.; GRANDO, C. M.; ANDREIS, R. F. Matemágica. In: ENCONTRO NACIONAL DE EDUCAÇÃO MATEMÁTICA, 11., Curitiba, 2013. Anais ... SBEM, 2013. Disponível em: <http://sbem.web1471.kinghost.net/anais/XIENEM/pdf/2173 625 ID.pdf>. Acesso em: 01 maio 2018.

ONUCHIC, L. de la R. Ensino-aprendizagem de matemática através da resolução de problemas. In: BICUDO, M. A. V. Pesquisa em Educação Matemática: Concepções e Perspectivas. São Paulo: Editora UNESP, 1999.

ONUCHIC, L. de la R.; ALLEVATO, N. S. G. Novas reflexões sobre o ensino-aprendizagem de Matemática através da Resolução de Problemas. In: BICUDO, M. A. V.; BORBA, M. de C. (Orgs.). Educação matemática: pesquisa em movimento. 3. ed. São Paulo: Cortez, 2009.

POLYA, G. A Arte de Resolver Problemas: um novo aspecto do método matemático. Trad. ARAÚJO, Heitor Lisboa de. Rio de Janeiro, 2006.

SAMPAIO, J. C.; MALAGUTTI, P. L. Mágicas, Matemática e outros mistérios. In: BIENAL DA SOCIEDADE BRASILEIRA DE MATEMÁTICA, 3., 2006. Universidade Federal de Goiás, UFSCar, 2006.

SMOLE, K. S.; DINIZ, M. I.; CÂNDIDO, P. Resolução de Problemas. Porto Alegre, Artmed, 2000. 